\title{
Diffuse alveolar haemorrhage - Is it an unusual or unlooked presentation of Fat Embolism Syndrome? A Case report and review of literature.
}

\author{
Dipesh Maskey ${ }^{1}$ \\ 'Consultant Pulmonologist, NH MMI Narayana Multispeciality Hospital, Raipur, Chattishgarh, India.
}

Keywords: Alveolar haemorrhage, fat embolism, femur fracture

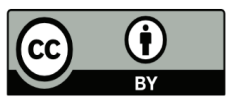

This work is licensed under a Creative Commons Attribution 4.0 Unported License.

\begin{abstract}
Fat embolism syndrome (FES) is a constellation of clinical symptoms characterized by a triad of respiratory insufficiency, altered sensorium and petechiae occurring after orthopaedic trauma or following surgical manipulation of long bones and spine. The diagnosis is based on clinical presentation and excluding other possible conditions. Beside histopathology, none of the investigations such as fat macroglobinuria in urine or lipid laden macrophages in bronchoalveolar lavage (BAL) is $100 \%$ specific. At times FES can present with atypical presentation such as intra alveolar haemorrhage and only high index of suspicion can help in making diagnosis.
\end{abstract}

\section{Introduction}

Fat embolism occurs when fat globules from the bone marrow enter the circulation mostly after orthopaedic trauma causing fractures of long bones, pelvis or vertebra. It also occurs following surgical fixation such as intramedullary nailing, instrumented spine surgery or vertebroplasty. ${ }^{1}$ Fat embolism syndrome (FES) is a constellation of clinical symptoms characterized by a triad of respiratory insufficiency, altered sensorium and petechiae. Not all patient with fat embolism develops FES. FES generally occurs within 24 hours of onset of trauma or post-surgery. ${ }^{1}$ The incidence of FES after trauma varies from $0.25 \%$ to $35 \%$. $^{\prime}$ The diagnosis is based on clinical presentation and excluding other possible conditions. Beside histopathology, none of the investigations such as fat macroglobinuria in urine or lipid laden macrophages in bronchoalveolar lavage (BAL) is $100 \%$ specific. Thus, various clinical criteria are available to improve the early diagnosis of FES but none are sensitive or specific. The most widely used clinical criteria is that of Gurd and Wilson which is more specific but less sensitive. ${ }^{2}$ At times FES can present with atypical presentation such as intra alveolar haemorrhage as in the case described below and only high index of suspicion can help in making diagnosis.

\section{Case Report:}

A 28 years healthy male sustained right closed femur shaft fracture in a road traffic accident. He had no history of loss of consciousness, vomiting, convulsions or any bleed. He underwent closed intramedullary nailing under spinal anaesthesia the following day which was uneventful. On $3^{\text {rd }}$ post-operative day he developed sudden onset shortness of breath, low grade fever and streaky haemoptysis. He was shifted to our institute the next day and was seen in emergency. He had no history of bleeding from other orifices. His past history was not significant. He has no history of addiction. On examination he appeared pale. His mentation was normal. His pulse rate was $92 / \mathrm{min}$ and regular, BP was $130 / 90 \mathrm{~mm} \mathrm{Hg}$, RR was $18 / \mathrm{min}$ and temperature was $98.60 \mathrm{~F}$. $\mathrm{His} \mathrm{SpO} 2$ was $93 \%$ in ambient air. His chest auscultation was clear with normal heart sounds. His abdomen was soft with no

\footnotetext{
*Correspondence Author:

Dr. Dipesh Maskey, MD, DM

Consultant Pulmonologist,

NH MMI Narayana Multispeciality Hospital,

Raipur, Chattishgarh, India-492001

Email: maskeyd@gmail.com

Phone: 918120452510
} 
organomegaly. The right thigh was slightly swollen compared to left. There was no evidence of petechiae or deep vein thrombosis in lower limbs. Fundoscopy was normal too. On laboratory investigations his CBC showed: Haemoglobin 7.5g/dl, TLC 15400/cC with $75 \%$ neutrophils, platelets $231000 / c c$. Prothrombin time 13.8 (control 13.5), APTT 29.5 seconds (control 27.5). His RFT and LFT was within normal limits. His previous reports were not available during admission so the treating orthopedician was contacted over the phone and discussed the case. His haemoglobin during admission was $12 \mathrm{~g} / \mathrm{dl}$ and had no significant bleeding during perioperative and immediate post-operative period and postoperative haemoglobin was $11.5 \mathrm{~g} / \mathrm{dl}$. An initial suspicion of fat embolism syndrome, pulmonary thromboembolism, pulmonary oedema and hospital acquired pneumonia were kept. His Chest X-ray taken in emergency showed bilateral infiltrate. An ECG showed normal sinus tachycardia and bedside 2D ECHO was normal. He underwent $\mathrm{CT}$ pulmonary angiogram that showed bilateral diffuse ground glass opacities with relative pleural sparing and no evidence of pulmonary embolism (figure 1). His urine routine microscopy was normal and no fat globules were identified. In view of sudden fall in haemoglobin, streaky haemoptysis and bilateral lung infiltrate a diffuse alveolar haemorrhage was suspected. He was admitted and received broad spectrum antibiotics (Meropenem and Teicoplanin) for MDR bacteria coverage, proton pump inhibitor. The next day he underwent flexible bronchoscopy with bronchoalveolar lavage (BAL) under conscious sedation that showed haemorrhagic effluent from both sides of lungs confirming diagnosis of alveolar haemorrhage (figure 2). BAL cytology revealed hemosiderin laden macrophages and few inflammatory cells predominantly neutrophils with full of RBCs. No lipid laden macrophages or fat globules identified. His autoimmune screening for ANA, ANCA and anti GBM was negative. BAL culture was sterile. His antibiotics were stopped and put on prophylactic oral antibiotics. He was transfused with one unit of packed RBC. His serial haemoglobin monitoring done daily showed no further fall and later discharged after 5 days of admission. A review literature provided us few case reports of fat embolism syndrome presenting as alveolar haemorrhage. Hence on deduction in an appropriate clinical scenario our patient too fits into the clinical criteria of fat embolism syndrome.

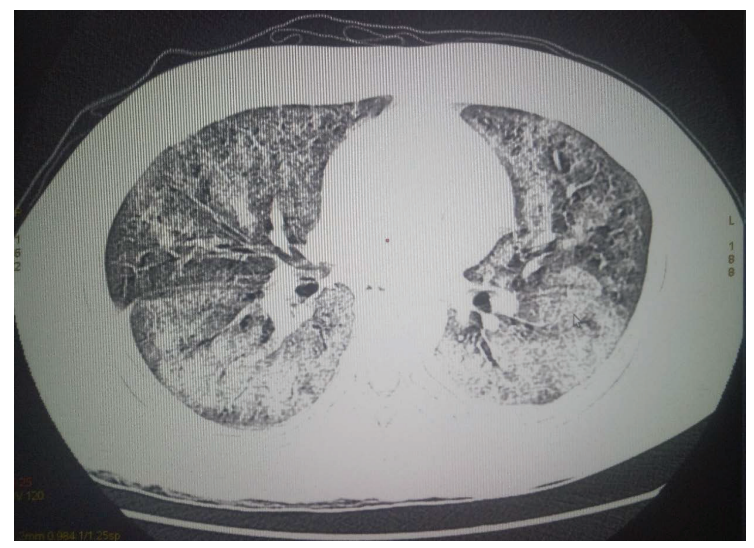

Figure 1. Computed tomography of lung showing bilateral alveolar opacities and ground glass opacities.

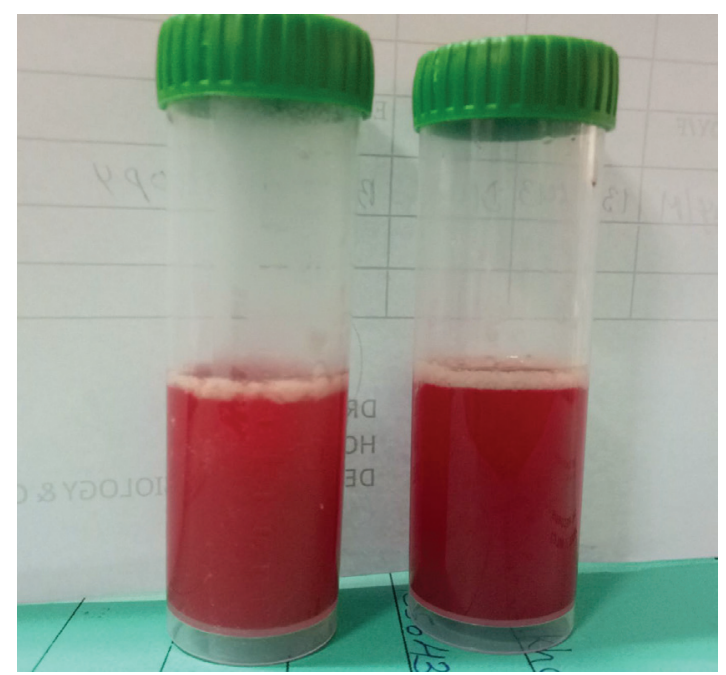

Figure 2. Bronchoalveolar lavage showing haemorrhagic effluent suggesting alveolar haemorrhage.

\section{Discussion:}

FES following trauma presenting as diffuse alveolar haemorrhage (DAH) is an unusual manifestation. A search in PubMed, Google and ResearchGate using search item "Fat embolism OR Fat embolism syndrome AND alveolar haemorrhage" lead to 11 cases published till date with 3 in French and remaining 5 in English. ${ }^{3-11}$ One case report was published as abstract presentation ${ }^{7}$ and another 1 as image of the week. ${ }^{5}$ The clinical characteristics of these cases is tabulated in table 1. The onset of symptoms is as early as 2 hours to 96 hours after the onset of trauma. Six cases had FES after performing surgery. The onset of FES after surgery was as early as during perioperative period to as late as 96 hours of surgery. Except for 1 patient whose data is not available rest all had recovered including our patient.

The pathogenesis of FES is a two-phase process and takes into consideration both the mechanical and biochemical hypothesis. Immediately after trauma or surgical intervention, the fat globules get embolized into circulation. From here these droplets gets mechanically trapped in pulmonary capillary bed leading to acute rise in pulmonary arterial pressure. If massive emboli occur, it may lead to circulatory collapse and even death rapidly. Smaller size fat droplets can pass through pulmonary capillaries to systemic circulation or via patent foramen ovale in the heart. The biochemical hypothesis explains FES due to degradation of fat globules by tissue lipase into fatty acids and other intermediaries that are proinflammatory. It leads to release of various cytokines damaging endothelial lining in lung, brain, skin and other organs. In lungs, it leads to damage of alveolocapillary endothelium producing interstitial oedema and haemorrhage with subsequent development of acute lung injury or ARDS. ${ }^{12}$ The biochemical theory explains the latency period by hours to days in development of FES post trauma or surgery as well as in nontraumatic FES. However, both mechanical and biochemical theories seem mutually inclusive rather than exclusive.

A suspicion of alveolar haemorrhage is made when an unexplained anaemia or sudden fall in haemoglobin with lung infiltrate is seen..$^{13}$ Sequential haemorrhagic effluent during bronchoscopic BAL confirms the diagnosis. Depending upon the clinical background, laboratory findings and/or lung histology; the aetiology of DAH is made. Alveolar haemorrhage occurs due to disruption of alveolocapillary basement membrane that can occur either due to injury 


\begin{tabular}{|c|c|c|c|c|c|c|c|c|c|c|c|}
\hline Case & Year & $\begin{array}{l}\text { Age } \\
\text { (years)/ } \\
\text { Sex }\end{array}$ & $\begin{array}{l}\text { Type of } \\
\text { fracture* }\end{array}$ & $\begin{array}{l}\text { Onset } \\
\text { of } \\
\text { symptoms } \\
\text { (hours) } \\
\text { after } \\
\text { trauma(T)/ } \\
\text { surgery(S) }\end{array}$ & Type of surgery\& & $\begin{array}{l}\text { CNS } \\
\text { involvement }\end{array}$ & Petechiea & Respiratory & Hemoptysis & $\begin{array}{l}\text { Need of } \\
\text { MV\# }\end{array}$ & Outcome \\
\hline 1 & 2018 & 44/Male & Left F,T,f & $24, \mathrm{~T}$ & & + & - & failure & + & + & Recovered \\
\hline 2 & 2018 & 73/Female & Right F & During $S$ & ORIF & - & - & + & + & + & Recovered \\
\hline 3 & 2014 & 33/Male & Right F & 96,5 & ORIF & - & - & + & + & NA & NA \\
\hline 4 & 2013 & 25/Male & Left F, H & $18, S$ & IMN & + & - & + & + & + & Recovered \\
\hline 5 & 2012 & 20/Male & Right A & $48, \mathrm{~S}$ & ORIF & - & - & + & - & - & Recovered \\
\hline 6 & 2011 & 37/Male & Right T & $29, \mathrm{~T}$ & & - & - & + & - & - & Recovered \\
\hline 7 & 2011 & 31/Male & $P$ & $\begin{array}{l}\text { Same day } \\
\text { of S }\end{array}$ & $\begin{array}{l}\text { Spinal } \\
\text { decompression }\end{array}$ & - & - & + & + & + & Recovered \\
\hline 8 & 2011 & 19/M & $P$ & $2, S$ & IMN & - & - & + & + & + & Recovered \\
\hline 9 & 2010 & 22/Male & $\mathrm{T}$ & $48, T$ & & - & - & + & + & - & Recovered \\
\hline 10 & 2001 & 21/Female & $\mathrm{T}$ & $96, \mathrm{~T}$ & & - & - & + & - & - & Recovered \\
\hline 11 & 1998 & 23/Male & Right F & $48, \mathrm{~T}$ & & - & - & + & - & - & Recovered \\
\hline
\end{tabular}

or inflammation of pulmonary capillaries, venules or arterioles. Three distinct histopathological pattern is seen: pulmonary capillaritis, bland pulmonary haemorrhage and diffuse alveolar damage. ${ }^{13}$ Surprisingly, none of the articles pertaining to DAH cite FES as a cause of DAH. ${ }^{13-15}$

But is alveolar haemorrhage an unusual presentation in FES? A PubMed search was made to find out research articles mentioning alveolar haemorrhage incidence in FES, but none of these literatures have focused on alveolar haemorrhage. ${ }^{16-18}$ FES is a clinical diagnosis based on an appropriate clinical scenario and the use of clinical criteria as proposed by either Gurd and Wilson, ${ }^{19}$ or Lindeque ${ }^{20}$ or Schoenfeld. ${ }^{21}$ However, none of them are prospectively validated or standardized. ${ }^{22}$ The most widely used Gurd and Wilson criteria is less sensitive but more specific than other criteria. ${ }^{2}$ In diagnosis of FES by Gurd and Wilson, unexplained anaemia or fall in haemoglobin by $20 \%$ is one of its minor criteria. The fall in haemoglobin due to lack of bronchoscopy in many of cases the diagnosis of alveolar haemorrhage remains elusive. The current author feels that it is underreporting rather than an unusual event. As the focus on bronchoalveolar lavage was to look for lipid laden macrophages rather than hemosiderin laden macrophages. Moreover, the presence of lipid laden macrophages was nonspecific in diagnosis of FES hence the routine use of bronchoscopy and BAL has gone against favour in those who meet the clinical criteria in the appropriate setting.

In a Serbian journal published in 2000 by Nikolic S et al, alveolar haemorrhage was found in about two third of autopsy cases of 56 patients who died of post traumatic FES. ${ }^{23}$

\section{Conclusion:}

Rapid fall in haemoglobin with new lung infiltrate in a patient with trauma can be a sign of fat embolism syndrome.
Conflict of interest:

None

Publication History:

Date of submission: March 3, 2020

Date of acceptance: May 15, 2020

\section{References}

[1] S. Akhtar, "Fat Embolism," Anesthesiol. Clin., vol. 27, no. 3, pp. 533-550, 2009.

[2] M. Piolanti et al., "Fat embolism syndrome: Lung computed tomography findings in 18 patients," J. Comput. Assist. Tomogr., vol. 40, no. 3, pp. 335-342, 2016.

[3] H. J. Lee, Jae Ha, Park, Jin Han, Kim, Yong Kyun, Kim, Ji Wan, Kim, Young Chang, Kim, Hyun-kuk, Jang, "A case of fat embolism syndrome accompanying diffuse alveolar hemorrhage," Hong Kong J. Emerg. Med., vol. 25, no. 3, pp. 160-162, 2018.

[4] J. Hui Suh, B. Lee, S. Ju Baek, S. Kyung Park, and E. Jung Cho, "A case of life-threatening intraoperative diffuse alveolar hemorrhage during a femur fracture operation with suspected fat embolism - A case report -," Anesth. Pain Med., vol. 13, pp. 77-81, Jan. 2018.

[5] J. Malo and K. Knox, Medical image of the week: fat embolism syndrome, vol. 8. 2014.

[6] S. K. Dash, A. Bansal, B. S. Wankhade, and R. Sharma, "Alveolar hemorrhage in a case of fat embolism syndrome: A case report with short systemic review," Lung India, vol. 30, no. 2, pp. 151-154, 2013.

[7] A. Alkhazna, A. Gohar, A. Saeed, and H. Taha, "Fat Embolism Syndrome Presenting as Diffuse Alveolar Hemorrhage," 
Chest, vol. 142142, no. MeetingAbstracts, 2012.

[8] P. F. Allan, D. K. Amjadi, and R. L. Haynes, “Diffuse alveolar hemorrhage: a rare manifestation of trauma.," Mil. Med., vol. 176, no. 9, pp. 1071-6, Sep. 2011.

[9] W. Ketata, S. Msaad, N. Bahloul, F. Marouen, and A. Ayoub, "Hémorragie intra-alvéolaire : présentation rare du syndrome d'embolie graisseuse," Rev. Mal. Respir., vol. 27, no. 9, pp. 1109-1113, Nov. 2010.

[10] M. Froidure et al., "[Fat embolism with lung hemorrhage].," Rev. Mal. Respir., vol. 18, no. 6 Pt 1, pp. 657-60, Dec. 2001.

[11] A. Guartite, R. al Harrar, F. Haida, B. Benyahia, and O. Abassi, "[Asphyxiating intra-alveolar hemorrhage: a rare form of fat embolism syndrome].," Ann. Fr. Anesth. Reanim., vol. 17, no. 7, pp. 743-6, 1998.

[12] E. E. Husebye, T. Lyberg, and O. Røise, "Bone marrow fat in the circulation: clinical entities and pathophysiological mechanisms," Injury, vol. 37, no. 4, pp. S8-S18, Oct. 2006.

[13] "The diffuse alveolar hemorrhage syndromes - UpToDate." [Online]. Available: https://www.uptodate.com/contents/ the-diffuse-alveolar-hemorrhage-syndromes. [Accessed: 28-May-20181.

[14] M. S. Park, "Diffuse alveolar hemorrhage.," Tuberc. Respir. Dis. (Seoul)., vol. 74, no. 4, pp. 151-62, Apr. 2013.

[15] O. C. loachimescu and J. K. Stoller, "Diffuse alveolar hemorrhage: diagnosing it and finding the cause.," Cleve. Clin. J. Med., vol. 75, no. 4, p. 258, 260, 264-5 passim, Apr. 2008.

[16] I. T. Tsai, C. J. Hsu, Y. H. Chen, Y. C. Fong, H. C. Hsu, and C. H. Tsai, "Fat embolism syndrome in long bone fracture-clinical experience in a tertiary referral center in Taiwan," J. Chinese Med. Assoc., vol. 73, no. 8, pp. 407-410, 2010.

[17] B. Gupta et al., "Analyzing fat embolism syndrome in trauma patients at AlIMS Apex Trauma Center, New Delhi, India.," J. Emerg. Trauma. Shock, vol. 4, no. 3, pp. 337-41, Jul. 2011.

[18] P. Koul et al., "Fat embolism syndrome in long bone trauma following vehicular accidents: Experience from a tertiary care hospital in north India," Lung India, vol. 30, no. 2, p. 97, Apr. 2013.

[19] A. R. Gurd and R. I. Wilson, "The fat embolism syndrome," Bone Joint J., vol. 56B, no. 3, pp. 408-416, 1974.

[20] B. G. Lindeque, H. S. Schoeman, G. F. Dommisse, M. C. Boeyens, and A. L. Vlok, "Fat embolism and the fat embolism syndrome. A double-blind therapeutic study.," J. Bone Joint Surg. Br., vol. 69, no. 1, pp. 128-31, Jan. 1987.

[21] S. A. Schonfeld et al., "Fat embolism prophylaxis with corticosteroids. A prospective study in high-risk patients.," Ann. Intern. Med., vol. 99, no. 4, pp. 438-43, Oct. 1983.

[22] E. Kosova, B. Bergmark, and G. Piazza, "Fat embolism syndrome.," Circulation, vol. 131, no. 3, pp. 317-20, Jan. 2015.

[23] S. Nikolić, J. Micić, S. Savić, and Z. Uzelac-Belovski, [Posttraumatic systemic fat embolism syndrome. Retrospective autopsy study], vol. 128. 2000. 